\title{
Quando a escrita ressignifica a vida: diários de um agricultor - uma prática de escrita "masculina"
}

\author{
Vania Grim Thies \\ Eliane Peres \\ Universidade Federal de Pelotas, Programa de Pós-Graduação em Educação
}

\section{Introdução}

Neste trabalho são apresentados resultados de uma pesquisa cujo objetivo geral é analisar práticas de letramentos de moradores de zonas rurais da região sul do Rio Grande do Sul. ${ }^{1}$ Trata-se de uma investigação

\footnotetext{
${ }^{1}$ Trata-se de um amplo projeto de pesquisa que abarca vários
} subprojetos. No caso dos letramentos rurais, três estudos são desenvolvidos: 1) análise do projeto Arca das Letras no Rio Grande do Sul, ligado ao Ministério do Desenvolvimento Agrário (programa de Bibliotecas Rurais da Secretaria de Reordenamento Agrário, criado em 2003 para facilitar o acesso aos livros e incentivar a leitura nos assentamentos da reforma agrária, nas comunidades de agricultores familiares e de remanescentes de quilombos); 2) estudo de práticas de leitura de moradores de comunidades rurais, enfatizando leituras de caráter histórico (leitores de História); 3) investigação de práticas de escrita de agricultores (escrita de diários por agricultores). Pela variedade e pelo grande volume de dados disponíveis na pesquisa, apenas parte deste último estudo é apresentado neste texto, que integra a dissertação de mestrado defendida no Programa de Pós-Graduação em Educação da Faculdade de Educação da Universidade Federal de Pelotas (Thies, 2008). que privilegia os letramentos em contextos não-escolares. As perguntas que se impõem inicialmente são: por que estudar práticas de letramento não-escolares de moradores de zonas rurais? Qual a contribuição de um estudo dessa natureza? É preciso levar em conta que estudos das práticas de letramento não-escolares se "inserem num conjunto mais amplo das práticas e disposições relacionadas ao consumo e à produção cultural” (Ribeiro, 2005, p. 25), oferecendo, portanto, referenciais importantes para pensar práticas educativas contemporâneas e questões sociais relevantes da atualidade. Além disso, Kleiman e Matencio (2005, p. 10) indicam que "o sucesso do letramento escolar depende da capacidade do professor de conhecer e se relacionar com práticas não-escolares de letramento construídas por outros agentes em outras instituições ou agências de letramento, que podem ser até mais bem-sucedidas no processo de introdução na cultura letrada”. Nessa direção, Ribeiro (1998, p. 12) argumenta que "o conhecimento sobre práticas de leitura e escrita não escolares [...] é essencial para orientar o trabalho da escola, de modo que cumpra mais adequadamente sua missão de principal agência de alfabetismo em nossa sociedade”. 
A proposta metodológica desta pesquisa vai na direção daquela indicada por Vóvio e Souza (2005) e Ribeiro (2005) que, baseadas principalmente em Lahire (2002, 2004, 2006), reivindicam a importância de estudos que buscam "compreender os processos sociais em escala individual”, defendendo a importância de "analisar o social também na escala do indivíduo" (Ribeiro, 2005, p. 27). Para Vóvio e Souza (2005, p. 46), "é preciso abrir espaços para a percepção das singularidades”. Contudo, segundo as autoras, "as investigações que assumem uma abordagem sociocultural sobre o letramento precisam combinar um conjunto diverso de situações investigadas” (2005, p. 50). É preciso, então, propor dispositivos metodológicos diversificados que gerem um conjunto variado de informações que permitam compreender quais os sentidos da leitura e da escrita na vida dos sujeitos.

Assim, nesta pesquisa, no intuito de identificar, descrever e analisar práticas de letramento de moradores de zonas rurais, todos agricultores com pouca escolaridade, utilizam-se diversificados instrumentos de coleta de dados. No caso do estudo em questão neste trabalho, da prática de escrita de diários por agricultores, ${ }^{2}$ associamos a análise dos próprios cadernos com entrevistas semiestruturadas. Realizamos leituras verticalizadas e horizontalizadas dos cadernos. Mapeamos e categorizamos as escritas dos diários tomando dias, meses, anos comparativamente (de um mesmo agricultor), além de estabelecer relações entre diários de irmãos, primos, pais e filhos.

Do ponto de vista da vinculação teórica, articulam-se, na investigação, estudos de autores ligados à história da cultura escrita ou àqueles que têm problematizado o conceito de cultura escrita ou cultura do escrito e autores que se ocupam de investigações no campo das práticas de letramento escolares e nãoescolares. Entre os primeiros destacam-se Chartier (1999, 2001, 2007), Petrucci (1999), Viñao Frago

${ }^{2}$ Foram coletados diários de três agricultores. Contudo, neste trabalho, analisamos apenas o conjunto de diários de um agricultor: Aldo Schmidt, 61 anos, que escreve diariamente desde 1972. Seus diários, considerados neste estudo, somam dez cadernos.
(1993, 1999, 2004), Gómez (2001, 2003, 2004), Britto (2004, 2005). Em relação aos segundos, as referências são: Soares (1995, 1998, 2004), Ribeiro (2004, 2005), Kleiman (2001) e Kleiman e Matencio (2005), principalmente.

\section{As contribuições dos estudiosos da história da cultura escrita}

Para Gómez (2003), a história da cultura escrita é "resultado de uma tríplice conjugação: história das normas, capacidades e usos da escrita, história do livro e, por extensão, dos objetos escritos (manuscritos, impressos, eletrônicos ou qualquer outro suporte) e história das maneiras e práticas de leitura” (p. 97). Na perspectiva do autor, a história da cultura escrita “deve constituir o ponto onde confluam duas tradições que até então haviam percorridos caminhos paralelos: de um lado a história da escrita e de outro a história do livro e da leitura” (p. 97-98).

Chartier (2001, p. 84) afirma:

\begin{abstract}
[...] não se pode falar de uma cultura do impresso, da leitura dos livros impressos, sem antes situar essa prática ou esses objetos em um marco mais amplo, que é o que define em uma sociedade a cultura do escrito. E a cultura do escrito vai desde o livro ou o jornal impresso até a mais ordinária, a mais cotidiana das produções escritas, as notas feitas em um caderno, as cartas enviadas, o escrito para si mesmo etc. [...] Na cultura do escrito há um continuum desde a prática da escrita ordinária até a prática da escrita literária.
\end{abstract}

Vivemos na era do “arquivar”, não só em papéis, mas em arquivos digitais, ou seja, em diferentes suportes. Há uma preocupação em deixar registros: uma forma de preservar o presente e, certamente, projetar o futuro. $\mathrm{O}$ escrito está nas ações e situações mais simples do dia a dia, como em uma placa na rua, e nas mais complexas, como em um formulário a ser preenchido, uma tese a ser elaborada, uma produção literária ou científica etc. Desse modo, a cultura escrita demonstra um modo de organização da sociedade. A cultura letrada "invade” o mundo das pessoas de mui- 
tas maneiras, seja através das propagandas na rua, das placas, das informações mais básicas ou de um modo mais sistemático, no mundo escolar e universitário.

Para Britto (2005, p. 15), a cultura escrita caracteriza

\footnotetext{
[...] um modo de organização social cuja base é a escrita

- algo que não se modificou em essência mesmo com o advento das novas tecnologias, resultantes do modo de fazer ciência e da organização do sistema produtivo que se constituíram na sociedade ocidental. [...] Cultura escrita implica valores, conhecimentos, modos de comportamentos que não se limitam ao uso objetivo do escrito.
}

Desde sua invenção, a escrita é símbolo de distinção e de poder. A divisão social entre analfabetos e alfabetizados continua fazendo da leitura e da escrita, nos dias atuais, sinal de poder e fator de hierarquização social.

Em relação à leitura, Chartier (2001, p. 126) argumenta que "há múltiplas práticas de leitura que não são necessariamente práticas cultas, ou profissionais, ou 'legítimas”, Para o autor, “cada leitor, para cada uma de suas leituras, em cada circunstância, é singular”. Mas essa singularidade é ela própria atravessada por aquilo que faz com que este leitor seja semelhante àqueles que pertencem à mesma comunidade (Chartier, 1999, p. 91-92). O mesmo vale para o caso da escrita: as pessoas são guiadas por intenções como colocar em ordem, administrar, registrar, estabelecer comunicação ou a tomada de identidade (Albert, 1993). Muitas vezes a escrita procura satisfazer necessidades individuais, dando sentido a essas práticas. Por isso é que podemos escrever desde uma lista de supermercado até sobre nossa vida privada ou íntima; cada produção é impulsionada por sentidos diferentes.

Ler e escrever são práticas que supõem muitas habilidades e só têm sentido quando situadas social e historicamente; portanto, na história da cultura escrita, leitura e escrita não podem ser vistas como práticas separadas. Soares $(1995$, p. 9) afirma que

[...] as habilidades e conhecimentos de escrita [...] devem ser utilizados diferencialmente para produzir uma grande diversidade de materiais escritos: desde a simples assinatura do nome ou a elaboração de uma lista de compras até a produção de um ensaio ou de uma tese de doutorado.

Ler e escrever são processos culturais que não podem ser reduzidos, pois cada indivíduo tem um processo mental e cognitivo diferente em cada situação. Na dimensão social, leitura e escrita implicam um conjunto de práticas sociais exercidas no contexto social: "é o que as pessoas fazem com as habilidades e conhecimentos de leitura e escrita em determinado contexto" (Soares, 1995, p. 10). Para a autora, ler e escrever não são categorias polares, mas sim complementares, que, na sua dimensão individual, exigem um conjunto de habilidades e conhecimentos linguísticos e psicológicos. Do mesmo modo, os conhecimentos da escrita, conforme a autora, "estendem-se desde a habilidade de simplesmente transcrever sons até a capacidade de comunicar-se adequadamente com um leitor potencial”. Dessa forma, entendem-se com mais clareza as práticas da escrita cotidiana dos agricultores, na medida em que permitem compreendê-las na sua dimensão social, histórica, cultural e, também, individual.

A localização e a análise dos diários do agricultor apresentado neste trabalho nos permitem entender a importância da cultura escrita, impedindo que materiais valiosos como esses acabem em cinzas ou no esquecimento. Há uma variedade de estudos sendo realizados com diários privados, cadernos de memórias, cadernos escolares, livros de contas, correspondências etc. (Mignot, Bastos \& Cunha, 2000), demonstrando a valorização da escrita em seu aspecto mais ordinário, ou seja, as "escritas ordinárias” (Fabre, $1993)$ tornaram-se hoje objeto de pesquisa acadêmica, indicando, em certa medida, a potencialidade das investigações sobre letramentos não-escolares para a compreensão do fenômeno da leitura e da escrita também na escola, como advertem Ribeiro (1998) e Kleiman e Matencio (2005).

Assim procuramos compreender a leitura e a escrita de moradores de zonas rurais: observando a grande diversidade do escrito nesses contextos e os 
muitos sentidos atribuídos à leitura e à escrita por esses sujeitos, que, via de regra, possuem pouca escolaridade mas alto grau de letramento. Os estudos do letramento são, aliás, outra contribuição teórica importante na pesquisa em questão.

\section{Os estudos do letramento: contribuições para compreender a leitura e a escrita entre moradores de zonas rurais}

O trabalho da pesquisa também procura colocar em evidência que escrita e leitura não são atividades vivenciadas somente no espaço urbano, mas o resultado de práticas sociais diferenciadas, visto que, na sociedade, há modelos e representações de escrita historicamente instituídos, que tomam essa prática, na maior parte das vezes, como atividade escolar e profissional e como sendo exclusiva de pessoas com alta escolaridade e/ou alto poder aquisitivo, que ocupam outros espaços sociais - a cidade, por exemplo. Por esse motivo, o estudo volta-se para a zona rural, pois, muitas vezes, esse espaço é considerado como o lugar apenas do trabalho braçal, "desprovido" de bens culturais. A escola e a zona urbana são tomadas como espaço educativo de acesso a bens culturais por excelência, entre eles a escrita. Nesse trabalho, buscamos mostrar que a escrita não é apenas uma prática "urbana", procurando desmistificar a falsa ideia de que ela inexiste no campo.

Ao analisarmos os dois opostos campo/cidade, sabemos que ambos têm interdependência, mas a cidade ainda é considerada o lugar “mais desenvolvido”, sendo desejado por muitos moradores da zona rural, o que resulta em muitos casos de migração no campo. Nesse sentido, o campo é "abandonado" por muitas pessoas que buscam na zona urbana a tão propalada oportunidade de ascensão social.

No caso desta pesquisa, a zona rural é o locus, os agricultores são os sujeitos e suas práticas de escrita é que estão em evidência. Através deste estudo, também pretendemos explicitar que há práticas sociais de escrita diferenciadas, por cujo desenvolvimento a escola não é a única responsável. Outras formas não-escolares de escrita são possíveis e existem sem serem muitas vezes reconhecidas socialmente, pois, quando pensamos em ler ou em escrever, imediatamente nos vêm à mente as práticas escolares ou as práticas profissionais formais do emprego da leitura e da escrita. Certamente o ambiente que marca sistematicamente essas duas habilidades é o escolar, mas o que podemos pensar é que fora da escola também se lê e se escreve de modos diversos, muito singulares, para as mais diferentes necessidades e motivações, nos mais diversificados grupos e espaços sociais, inclusive independente do nível de escolaridade das pessoas.

Os estudos em andamento na pesquisa sobre letramentos rurais indicam que cada vez mais os sujeitos escrevem fora do ambiente escolar e das regras formais, mas como uma prática muito singular e que se opõe à produção científica e literária. São escritas de vida que carregam alegrias e tristezas, conquistas e perdas, escritas dos acontecimentos do mundo cotidiano - como os diários do agricultor que apresentamos neste texto. As escritas ordinárias são assim caracterizadas: servem para contar o dia de um modo muito particular, criando o seu próprio estilo, e é por isso que aparecem também em diferentes suportes (diários, livros de memórias, blogs etc.). O trabalho desenvolvido por Silva e Batista (2005, p. 4) sobre as escritas de um grupo de docentes confirma que:

\footnotetext{
O universo das écritures ordinaires se opõe ao universo prestigiado das escritas literária e científica, que têm o objetivo de fazer uma obra e consagrar um autor ou uma autoridade. A escrita cotidiana associa-se à rotina das ocupações cotidianas e tem como função laisse trace. ${ }^{3}$
}

As escritas ordinárias (enquanto fontes de pesquisa) impõem um verdadeiro "mistério": qual o sentido da escrita de diários para as "pessoas comuns" (Gomes, 2004)? Que sentimentos os movem à escrita cotidiana, como o caso de um agricultor com pouca escolaridade? Essas, entre outras questões, é que temos

\footnotetext{
${ }^{3}$ Os termos écritures ordinaires e laice trace são de Daniel
} Fabre (1993) (cf. Silva \& Batista, 2005, p. 4). 
procurado problematizar ao analisar, especialmente no estudo sobre diários de agricultores.

Por isso, apresentamos a escrita de diários como um fenômeno de letramento não-escolar. Para Soares (1998, p. 18), letramento é “o resultado da ação de ensinar ou de aprender a ler e escrever: o estado ou a condição que adquire um grupo social ou um indivíduo como consequência de ter-se apropriado da escrita”.

Para Kleiman (2001, p. 19), letramento pode ser definido como "um conjunto de práticas sociais que usam a escrita enquanto sistema simbólico e enquanto tecnologia, em contextos específicos, para objetivos específicos".

Um indivíduo pode ter um alto nível de escolaridade e não fazer uso sistemático das práticas de escrita ou de leitura; ou pode acontecer o inverso, como no caso do agricultor em questão: baixo nível de alfabetização ou de escolarização e uso constante e cotidiano da escrita. Nesse sentido, o conceito de letramento é fundamental. Esse reconhecimento pode ser observado também em uma pesquisa extensiva e monográfica com agricultores e sua relação com a literacia ${ }^{4}$ em Portugal:

Reconhecendo-se, hoje, que a alfabetização das populações não significa linearmente o seu domínio da leitura e da escrita, é proposto o conceito de literacia como capacidade de processamento de informação escrita no trabalho, nas atividades domésticas e na comunidade. O que está, deste modo, em causa não é somente a aquisição das competências de leitura e escrita, mas o modo como estas são exercidas, face às necessidades vividas e experimentadas no dia-a-dia. (Dias, 1996, p. 358)

Assim, este estudo também pretende discutir as questões da escrita, problematizando as "fronteiras" entre alfabetizados, analfabetos, semialfabetizados etc. Os resultados da pesquisa do Indicador Nacional de Alfabetismo Funcional (INAF) de 2001, por exemplo, apontaram diferentes "níveis de alfabetismo" (1, 2, 3

${ }^{4}$ Palavra utilizada em Portugal equivalente a letramento no Brasil. Ver Soares (2006). e analfabeto), ${ }^{5}$ referindo-se as "práticas de leitura e escrita, à presença da linguagem escrita na cultura, à relação desse fenômeno com a escolarização" (Ribeiro, 2004, p. 12). A pesquisa anual do INAF mostra as diferenças e as variações do fenômeno do analfabetismo e do alfabetismo, apontando, assim, para a necessidade de estudos monográficos que mostrem que não há uma única regra ou conceitos únicos (alfabetizados e analfabetos, por exemplo) quando se aborda a questão da leitura e da escrita. Há singularidades que precisam ser destacadas e discutidas em uma perspectiva cultural e social, como é o caso deste estudo.

Para Ribeiro (2005, p. 19), o conceito de letramento como fenômeno social complexo abarca "diversos graus e tipos de habilidades de uso da língua escrita e seu uso efetivo em práticas sociais, assim como o modo como indivíduos e grupos atribuem significados a essas habilidades e práticas". É nessa perspectiva que temos identificado várias práticas de leitura e de escrita entre moradores de zonas rurais; "usuários" competentes da leitura e da escrita, naqueles contextos e naquelas situações, que ressignificam a vida através das práticas de ler e escrever. Essas situações são as mais variadas possíveis: desde a leitura de romances, da Bíblia, de "livros de história” até a escrita de poesias e de diários. Do conjunto de dados de que dispomos na pesquisa, optamos por apresentar o caso de um agricultor que há 36 anos $^{6}$ escreve diários ininterruptamente, cotidianamente, sem deixar a escrita do diário por um dia nem delegá-la a outra pessoa.

${ }^{5}$ Nível 1 de alfabetismo: corresponde às pessoas com capacidade de localizar informações explícitas em textos muito curtos. Nível 2 de alfabetismo: corresponde às pessoas com capacidade de localizar informações em textos curtos. Nível 3 de alfabetismo: corresponde às pessoas com capacidade de ler textos mais longos. Analfabeto: corresponde as pessoas que não completaram nenhuma série escolar ou completaram de uma a três séries.

${ }^{6}$ A análise dos diários foi realizada até o ano de 2004, portanto, 32 anos de escrita foram considerados neste estudo. No entanto, há, ainda, um diário em uso pelo agricultor que cobre o ano de 2004 até o momento da pesquisa, 2008, totalizando 36 anos dessa prática ininterrupta. 


\section{Quando a escrita ressignifica a vida: diários de um agricultor}

É possível, através da escrita, como indica Chartier (2007, p. 9), fixar traços do passado, trazer as lembranças dos mortos ou a glória dos vivos. Para o autor, historicamente a escrita teve "por missão conjurar contra a fatalidade da perda” (2007, p. 9). No sentido de não deixar que nada se perca, encontramos os diários de agricultores que, através de seus registros, ressignificam sua história realizando observações importantes quanto ao trabalho da lavoura, ao tempo e ao clima, ao lazer e aos acontecimentos pessoais e sociais da vida comunitária. Apresentamos então o exemplo do agricultor Aldo Schmidt, ${ }^{7}$ de 61 anos, que há 36 anos (1972-2008) registra sua vida por escrito, embora tenha apenas o ensino primário; trata-se, portanto, de uma "pessoa comum" que ganha "voz" através dos seus diários, escrevendo rigorosamente todos os dias e deixando marcas de sua própria história através da escrita. Desse período, consideramos os 10 diários que cobrem os anos de 1972 até 2004, ou seja, 32 anos ininterruptos de registro cotidiano. Isso se deve ao fato de o agricultor disponibilizar esse material; um caderno ainda está em uso (2004-2008). Os 10 cadernos transformados em diários que são analisados nesta pesquisa estão assim organizados:

- Diário n. 1: 5 de julho de 1972 a 17 de fevereiro de 1976

- Diário n. 2: 18 de fevereiro de 1976 a 16 de junho de 1979

- Diário n. 3: 17 de junho de 1979 a 31 de dezembro de 1984

- Diário n. 4: $1^{\circ}$ de janeiro de 1985 a 31 de dezembro de 1987

- Diário n 5: $1^{\circ}$ de janeiro de 1988 a 11 de março de 1991

- Diário n. 6: 12 de março de 1991 a 31 de dezembro de 1994

${ }^{7}$ A utilização do nome e dos dados pessoais contidos neste texto e na dissertação de mestrado foi negociada, dialogada e autorizada por escrito.
- Diário n. 7: $1^{\circ}$ de janeiro de 1995 a 10 de julho de 1997

- Diário n. 8: 11 de julho de 1997 a 17 de fevereiro de 2000

- Diário n. 9: 18 de fevereiro de 2000 a 27 de agosto de 2002

- Diário n. 10: 28 de agosto de 2002 a 31 de dezembro de 2004

Aldo Schmidt, segundo filho mais velho de uma família de doze irmãos, iniciou a escrita de diários no ano de 1972, especificamente na data em que completava 25 anos e morava com seu pai e os irmãos na Colônia Santa Áurea, município de Pelotas (RS):

\begin{abstract}
A partir do dia 5 de julho de 1972 foi iniciado este diário, que se segue aos 25 anos de idade. Os 25 verões que já passei já ficaram tão distante, mas ainda me lembro dos principais fatos: à iniciar por minha infância por volta do 20 mês de agosto do ano de 1953 pela primeira vez suportei uma fratura quando fraturei a perna brincando de bonde numas conjuntas que meu pai estendia: foi um choque com meu irmão Cleber caímos e não levantei: pela $1^{\mathrm{a}}$ vez era transportado para um hospital, por meu pai, fui internado na Beneficiencia Portuguesa, sendo minha madrinha tia Amália que me cuidou no hospital; Tirando uns 5 dias baixado voltei para casa com a perna ingeçada ficando quase um mês sem poder caminhar, depois de desengeçada a perna voltei a vida normal. (Aldo Schmidt, Diário n. 1, jul. 1972)
\end{abstract}

Os “25 verões” são, então, recuperados através da escrita que se inicia como reproduzido acima. Depois disso, 5 de julho de 1972, Aldo não mais parou de escrever: sobre si, sobre o trabalho, o lazer, o casamento, a esposa, os filhos, entre outras coisas.

Atualmente mora com a esposa e os dois filhos na Colônia Santo Antônio, $7^{\circ}$ distrito de Pelotas (RS). Possui em torno de 20 hectares de terra para o cultivo de suas lavouras, trabalho realizado com mão de obra familiar. Além disso, arrenda ${ }^{8}$ alguns hectares, em

\footnotetext{
${ }^{8}$ Arrendar é o mesmo que "alugar”. Nesse sistema, o ar-
} rendatário "paga" as terras arrendadas com o produto colhido, conforme o acerto realizado. 
terras vizinhas para o plantio de suas culturas. Os dois filhos, Enoir (28 anos) e Mateus (21 anos), concluíram o ensino médio em uma escola na zona rural e trabalham na lavoura com Aldo e Nair. A família ocupa-se com a plantação de vassouras, milho, frutas (pêssego e laranja) e com produção de leite. Sua casa localiza-se em um terreno alto, sendo avistada da estrada principal da localidade. Ao lado direito do caminho de chegada está a plantação de laranjeiras e, ao fundo da casa, os galpões da propriedade. Em fevereiro de 2007, data da entrevista, Aldo preparava a secagem das vassouras. Esse vegetal, depois de seco, serve para a fabricação de vassouras, justificativa do próprio nome do objeto doméstico.

Na entrevista realizada com Aldo, ele revelou o que sente em relação aos diários com uma simples frase: "aqui está toda a minha vida", deixando sobre a mesa os onze cadernos escritos ${ }^{9}$ e disponibilizados com orgulho para a pesquisa. Ao dizer isso, Aldo atribui um sentido para sua prática de escrita: deixar a sua vida por escrito, na forma de uma "escrita de si” (Gomes, 2004). Para ele, o diário é "ato biográfico", pois dá um significado especial para algo que está diretamente relacionado à sua vida: a prática da escrita. Assim como o trabalho com a terra é importante, porque dela retira seu sustento e é sua forma de vida, a escrita também é, pois é o que "sustenta” a "produção de si".

O começo da escrita compõe-se de algumas páginas rememorando sua infância e os principais fatos de sua vida até a idade dos vinte e cinco anos, em julho de 1972. Dessa forma, Aldo narra a sua vida até, como ele próprio diz, seus "25 verões”. Com isso, toma "distância de si mesmo" para enxergar-se, produzir-se enquanto sujeito que pertence ao mundo rural. Escreve com as mãos calejadas pelo arado, pela enxada que cava a terra, assim como a caneta que marca sua escrita no diário. Escreve para trazer o passado vivido para o presente.

${ }^{9}$ Os dez diários que foram analisados na pesquisa, mais o que Aldo estava escrevendo no momento da realização da investigação (2008).
No primeiro diário, traz recordações do tempo da infância, do primeiro dia de aula: "no dia 5 de março de 1955 pela primeira vez me arrumava para ir para a aula”; as notas escolares registradas com precisão; a Copa do Mundo de 1962 no Chile - "quando Brasil foi bi-campeão"; o primeiro baile - "no dia 8 do mês de maio de 1966 fui ao $1^{\circ}$ baile no Salão Bosembecker”; o ingresso no quartel e os colegas de pelotão desse período; seus deslocamentos para outras cidades; seus treinamentos; suas pretendentes; a primeira carta de amor; a primeira visita à casa da namorada, Nair Belletti - "pela $1^{\mathrm{a}}$ vez chegava a sua residência para lhe visitar”; a sua eleição como membro de uma comunidade religiosa.

Com sua narrativa, Aldo realiza um olhar sobre si (Souza, 2006, p. 102) através do tempo, recordando para revelar-se. Nas palavras de Souza:

\begin{abstract}
A arte de lembrar remete o sujeito a observar-se numa dimen-
são genealógica, como um processo de recuperação do eu, e a memória narrativa marca um olhar sobre si em diferentes tempos e espaços, os quais se articulam com as lembranças e as possibilidades de narrar as experiências. O tempo é memória, o tempo instala-se nas vivências circunscritas em momentos; o tempo é o situar-se no passado e no presente.
\end{abstract}

No caso dos diários, o domínio do tempo é um fator importante, pois a escrita de si deseja reter o tempo, constituindo o lugar da memória. O tempo é o vínculo entre a memória e o que foi vivido.

Para Aldo, a escrita era e continua sendo uma necessidade "bem intencionada", conforme Artières (1998, p. 11), que nesses casos caracteriza-se como "o arquivamento do eu ou a intenção autobiográfica". Poderíamos acrescentar que esses aspectos fazem parte do processo de construção da subjetividade do sujeito através de sua escrita, ou seja, o processo de arquivar a própria vida acaba por produzir a própria identidade. Por isso sua narrativa ganha significado, pois tem na experiência sua base existencial (Souza, 2006). Aldo cultiva a lavoura e "cultiva" também seus diários e, assim, as escritas ganham sentido em sua vida: o de constituir-se como sujeito. 
Seus três primeiros diários são encapados com papel colorido e com um plástico, dando aspecto de cuidado; em todos eles as linhas são preenchidas, dia a dia, sem espaçamentos, mas com uma caligrafia bem legível. Isso faz perceber seu gosto e zelo pelos diários. A seguir está um exemplo da sua forma do registro.

Figura 1: Fragmento do Diário n. 3, julho de 1979

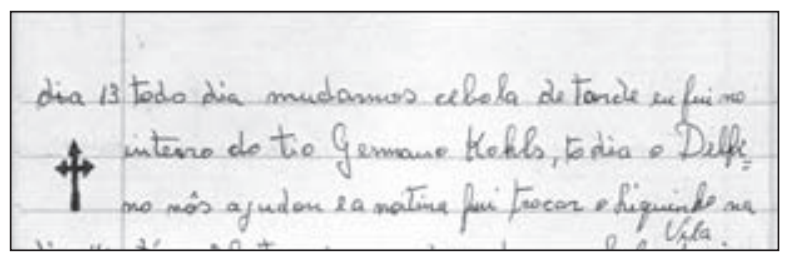

Na entrevista, observa-se um fato interessante em relação às suas explicações para as escritas dos diários:

Eu sou um meio esquecido, bastante esquecido, não, relaxado. Porque eu anoto ali, eu sei que tá anotado e aquilo não me fica na cabeça, né? Então se alguém me pergunta alguma coisa: ah, tem que olhar! [...] Tu relaxa a mente.

(Aldo Schmidt, entrevista, 8 fev. 2007)

A escrita de Aldo permite, também, uma forma de memória: escreve no diário e, em consequência, desenvolve também uma prática de leitura, ou seja, "revisita" suas escritas sempre que necessário, apontando para a relação intrínseca e não polar entre leitura e escrita de que nos fala Soares (1995). Pensando a escrita enquanto estratégia de memória, Aldo deixa claro que é também, além de outras funções, uma estratégia de lembrança. Nas escritas do agricultor, ao folhear a página do diário, o dia que ficou ali registrado é imediatamente recuperado através do papel: detalhes do tempo, do trabalho, do lazer, de acontecimentos importantes, de como foi exatamente aquele dia. Tudo é visualizado em questão de instantes:

Às vezes eu pego um caderno desses aí, e eu leio aí, tal dia tal, o que foi feito eu me lembro, como se eu tivesse feito ontem! Então um dos fatores que me levou a fazer isso aí é: o passado trazendo o presente de novo. (Aldo Schmidt, 2007)
A possibilidade de ter "o passado presente de novo" é um dos sentidos da escrita para Aldo. Mas ele não escreve simplesmente para "lembrar fatos", acompanhar e controlar o trabalho na lavoura, mas sobretudo para produzir sua identidade, deixar sua vida por escrito, narrar sua existência, estruturar um olhar sobre si, revelar-se (Souza, 2006). Nesse sentido é que afirma que escrever "relaxa" a mente. Não se pode esquecer de que durante o dia o trabalho de Aldo é duro e pesado: arar, capinar, plantar, colher etc., em uma propriedade onde a família trabalha coletivamente para o próprio sustento.

É importante enfatizar que Aldo registra seus “25 verões” em seus diários, nos 32 anos que consideramos na análise, sem deixar a escrita sequer por um dia; além disso, a contabilidade da casa também é "controlada" através de registros escritos. Sua renda, “entradas e saídas” também são registradas em cadernos separados dos diários, desde o ano de 1976. Mais uma vez, percebe-se que os sentidos da escrita de diários para Aldo não é apenas o seu trabalho, como ele afirmou em entrevista, pois, se assim fosse, o caderno de contabilidade seria suficiente para o controle de suas atividades profissionais.

Aldo justifica o começo de suas anotações referentes à contabilidade da casa:

No tempo de solteiro, isso não, o negócio do financeiro
não entrava; agora, depois que eu comecei a trabalhar por
minha conta, eu tenho anotado tim tim por tim tim, se é
com higiene, se é com saúde, se é com veneno, se é com
diversão, despesa, e a entrada também com que que foi. (Aldo Schmidt, entrevista, 8 fev. 2007)

Os cadernos de contabilidade da casa, com o controle dos lucros e despesas, não foram abordados em profundidade nesse estudo. São apresentados para, mais uma vez, mostrar que os registros de Aldo têm características diferenciadas: nada escapa de suas escritas, nem os gastos com higiene ou saúde, tudo é minuciosamente registrado. Os diários, contudo, têm uma dimensão mais pessoal e privada.

Com sua escrita, ele deixa uma herança para sua família. Enoir, seu filho mais velho, contou, em 8 de 
fevereiro de 2007, no dia da entrevista (participaram da conversa o irmão de Aldo, a esposa e o filho), que também começou a escrita de diários, segundo ele, de maneira bem mais simples que a do pai, fato que merecerá atenção para uma futura análise. Por ora, detalhemos um pouco mais a escrita de Aldo.

\section{Os diários de Aldo: uma prática de escrita "masculina"}

Acompanhar a vida de Aldo através de seu diário proporcionou um grande “deslumbramento", afetivo e emocional. Pela leitura atenta dos cadernos, percebe-se a história da família, desde o namoro, o noivado, o casamento, a constituição da nova família, o nascimento dos filhos. Em 29 de maio de 1976 há o registro do dia do casamento de Aldo:

Dia 29 levantamos às 4,30h. sob forte garua, demos os últimos retoques para o nosso dia, às $7 \mathrm{~h}$ fui me mudar e as 8,30 h. saímos eu e a minha noiva para o cartório na condução de Lindolfo Bachini, chegando no cartório 9h. e as 9.15h. nós nos casamos sendo os meus testemunhos Lindolfo Bachini e Daizi Schiller Bachini: e da Nair, Vitor Casari e Darli Romano Casari; sendo que as 10h. saímos do cartório casados passando apartir desta hora a fazer parte de minha_vida e entrando no nosso diário: chegamos em casa de Ernesto Belleti 11h. e almoçamos e as 11,30h. a Nair foi se vestir de noiva para o ato religioso, saímos para a Igreja as 12:30h. chegando na paróquia Divino Salvador as $13.30 \mathrm{~h}$. e as 13,45 eu entrava na nave da Igreja onde esperei ela que entrou as $13,50 \mathrm{~h}$. e as 14,15 estavamos casados perante Deus sendo nossos padrinhos Clovis Schmidt e esposa, Elmar Veiga e esposa (do meu lado) e José Melo e esposa e Flavio Schiller e esposa (do lado dela) e sendo a nossa aia a garotinha Vânia Mayer Schmidt, após recebemos as felissitações às $14,30 \mathrm{~h}$. retornamos para o restante das festividades chegando às 15,00h. daí até as 19,30h. quando iniciamos a reunir os nossos presentes, e as 20,45h. despedimos-nos de nossos familiares e saímos no caminhão de Henrique P. Schmidt em direção a nossa casinha, chegando em casa às 22h. abrimos a porta de nosso lar nesta hora. (Aldo Schmidt, Diário n. 2, maio 1976)
Nair Belletti “entra na vida” e, portanto, no diário de Aldo. Além disso, a esposa assina, de próprio punho, o diário nesse dia, demonstrando a importância desse registro na vida de Aldo.

A esposa não se torna (co)autora dos diários, pois ele continua escrevendo na primeira pessoa. Contudo, a assinatura no diário no dia do casamento pode ter significado, de alguma forma, o esforço de Aldo no sentido de obter a "permissão" da esposa para continuar a escrever, uma vez que essa não era uma prática vivenciada por ela, o que poderia, talvez, causar um certo "estranhamento". Com o ato, o agricultor pode ter buscado legitimidade da esposa para a prática da escrita; afinal era/é uma atividade que realiza todas as noites, depois da lida diária na lavoura, antes de deitar-se.

Ao que tudo indica, nesse caso, o casamento fortaleceu o diário, ao contrário de exemplos de diários íntimos femininos que são queimados antes do casamento como forma de "apagar o passado", "esconder" do marido as "letras em confidência" (Perrot, 2005). Nas palavras da autora, referindo-se às escritas femininas, o casamento sempre mata o diário. Para Aldo, ao contrário, o casamento solidificou a escrita na nova família.

O conteúdo dos diários, conforme percebemos através da análise, não foi alterado, mas é importante observar que, após o casamento, Aldo passou a realizar os registros na sua nova casa, o que implica outros espaços, compromissos e novos sujeitos. Antes era um diário de Aldo na condição de rapaz solteiro, na casa paterna; depois do casamento, seu diário passou a ter registros de outras pessoas, de outros espaços e de outras emoções, como foi o caso do registro do nascimento dos filhos.

Um fato bastante interessante referente à escrita de Aldo é o de ser uma prática continuada: o irmão costumava escrever, as irmãs solteiras, que continuam na casa do pai, atualmente escrevem seus diários, mas só Aldo escreve ininterruptamente. Ele casou e incluiu a esposa nos registros, e agora os filhos também escrevem seus diários. O fato é que a prática de escrita é, de certa forma, uma herança cultural da família Schmidt. 
Depois do casamento, os relatos escritos nos diários de Aldo ficam cada vez mais detalhados, nos mais diferentes aspectos: a esposa, os filhos, o lazer, o trabalho. O fato é que, ao "entrar" no cotidiano da vida de uma pessoa, encontramos fatos que aparecem imbricados e de difícil separação; o privado, por ora, parece misturar-se com o íntimo. Ou seja, fatos da vida familiar e coletiva da família misturam-se com os sentimentos. Nesse caso, conforme afirma Foisil (1991, p. 331), é preciso saber ler nas entrelinhas do escrito:

\begin{abstract}
Não é fácil penetrar na vida privada nem na vida íntima situada no interior da vida cotidiana, ou porque se confundem com a vida pública, ou porque, ao contrário, se escondem atrás do próprio pudor em revelá-las. Pesquisá-las em memórias, diários e livres de raison visa não a construir, a partir de incidentes e fatos curiosos, uma vida privada contida no relato - muitas vezes brilhante - de numerosas vidas cotidianas, e sim a entender como as mentalidades a percebem.
\end{abstract}

$\mathrm{Na}$ análise dos diários de Aldo, especialmente depois de seu casamento em 1976, é recorrente a escrita sobre a esposa, os filhos e acontecimentos marcantes na vida deles, bem como fatos ligados ao trabalho rural. O cotidiano da vida e os aspectos sentimentais, embora às vezes implícitos, são recorrentes nos registros diários.

A “guarda da memória” realizada por Aldo aparece várias vezes, conforme se percebe no dia do noivado, do casamento, e em inúmeras vezes ao longo dos diários:

Dia $1^{\mathrm{o}}$; dia que pela $1^{\mathrm{a}}$ vez colocava uma aliança em sinal de meu noivado com Nair Belleti: e os outros foram a dança no Joaquim Mayer e o Cleber voou para Canguçu. (Aldo Schmidt, Diário n. 1, jan. 1973)

Aldo é atento a todos os fatos que acontecem pela primeira vez em sua vida, como se fossem ritos de passagem no seu "arquivamento": a $1^{a}$ visita à casa de Nair, a $1^{a} v e z$ que colocava a aliança, a $1^{a} v e z$ que vestiu a camiseta de seu time, a $1^{a}$ vez que pegou o filho nos braços, são exemplos do caráter simbólico do registro. Sua maneira de dizer a vida por escrito é carregada de simbolismos, de sentidos e de sentimentos. Observamos isso com maior frequência depois que Nair entra no diário:

Dia 1. de manhã eu fui ao Monte Bonito ${ }^{10}$ na casa de Paulo Schaglhoni para arrumar negocio para uma junta de boi da Nair e de volta passei pela casa do Sogro velho de tarde trabalhei no galpão junto com o Clenderci e o Cledinei; e a Nair todo dia capinou a cebolinha e terminou; ao meio dia pela $1^{\text {a }}$ vez demos uma passiada na lavoura que nos pertencem para cultivar. (Aldo Schmidt, Diário n. 2, jun. 1976)

De certa forma, o casamento com Nair foi um rito de passagem, um acontecimento carregado de afetividade e de um sentimento de "pertencimento compartilhado". Assim é que o "primeiro passeio na sua lavoura”, "na lavoura que nos pertence”, ganha sentido.

Encontramos mais uma escrita semelhante; dessa vez os detalhes estão voltados para o primeiro passeio com a esposa depois do casamento:

Dia 13 domingo de manhã biscateamos ${ }^{11}$ eu fui lá no Clóvis orientar ele na construção do chaminé, e de tarde fomos passear pela primeira vês depois de casados fomos lá no tio Francisco e na volta chegamos no Paulo. (Aldo Schmidt, Diário n. 2, jun. 1976)

Para Bahia (2000), os ritos de passagem marcam os momentos críticos no ciclo de desenvolvimento e, também, a transformação do indivíduo, o que se observa para o caso de Aldo. A $1^{a}$ vez marca uma transformação em sua vida: o primeiro passeio com a esposa em suas lavouras, o primeiro passeio na casa de parentes, o primeiro filho, entre outros.

\footnotetext{
${ }^{10}$ Localidade da zona rural do município de Pelotas.

${ }^{11}$ Segundo a entrevista com Aldo (8 fev. 2007), o biscatear “é
} o serviço da volta, é fazer uma coisinha e outra”. São os “pequenos trabalhos” realizados em torno da casa. 
Com o tempo, depois do nascimento dos filhos, Nair, a mulher, a companheira de jornada, muda de "lugar" nos registros, passando a ser chamada de "mãe":

Dia 19 de manhã eu rachei lenha de cipreste e a mãe roçou nas peras do viveiro de tarde fizemos um tratamento de veneno nos Precocinhos e nos Aldrigues. ${ }^{12}$ (Aldo Schmidt, Diário n. 7, maio 1995)

Dia 8 eu fui a Pelotas de carro levar o Vô Schmidt a mãe de manhã foi no dentista na Vila ${ }^{13}$ e de tarde capinou vassoura. (Aldo Schmidt, Diário n. 9, nov. 2000)

Dia 27 até (geada) as 9h eu e o Enoir derrubamos um eucalipto para uma linha no galpão a mãe podou as roseiras, e depois quebramos milho na costa. (Aldo Schmidt, Diário n. 7, jun. 1997)

A partir desses traços específicos da escrita de Aldo, ao folhear os diários, pôde-se ver uma escrita masculina viva de memórias, histórias, sentimentos e "rituais", como forma de justificar o tempo passado (Artières, 1998), trazendo-o ao presente, conforme Aldo afirmou em seus relatos: "então um dos fatores que me levou a fazer isso aí é: o passado trazendo o presente de novo" (Aldo Schmidt, 8 abr. 2007).

Os filhos são nomeados nos diários de Aldo desde o nascimento, inclusive no que diz respeito aos sentimentos de ser pai. Os dois filhos de Aldo, Enoir e Mateus, ainda moram com os pais e trabalham no cultivo da terra. O dia do nascimento do filho mais velho, Enoir, em maio de 1981, destaca-se com mais de uma folha de escritas no diário. Observamos um pouco da riqueza desse relato, que revela a emoção de ser pai:

Dia 11 as $0,30 \mathrm{~h}$ a Nair sentiu-se em movimento para o parto, aguardamos uns minutos para ter sertesa, quando

${ }^{12}$ Nomes dados a variedades de pêssegos.

${ }^{13}$ Localidade da zona rural de Pelotas chamada de Vila Nova, onde há um pequeno centro com posto de gasolina, igreja, comércios etc. sai a procura do carro do Zildo Torres que chegou aqui 2,15h. e saímos para Pelotas as $2,45 \mathrm{~h}$ e chegamos no Pronto Socorro da $\mathrm{St}^{\mathrm{a}}$ casa as 3,45 e enseguida subiu para a Enfermaria Rural e ali ficando até as $10 \mathrm{~h}$ quando foi levada para o Bloco Sirurjico para se submeter há uma intervenção Sesariana, e as 10,5 deu entrada na sala da operação e as 10,30h deu a luz ao nosso filho Enoir (que apartir desta hora pasa a ser nosso $1^{\circ}$ erdeiro) às $11 \mathrm{~h}$ foi levado para o $1^{\circ}$ banho e colocado no berçário, às $11.20 \mathrm{~h}$, lá Nair entrou em recuperação saindo para a Enfermaria as $2,30 \mathrm{~h}$ da tarde e as $5,15 \mathrm{~h}$ pela primeira vez tomava o nosso filhinho nos braços e levei do berçário, até a Enfermaria para a Nair ver nosso pequeno Enoir esta hora o nosso primeiro, nós os treis juntinhos e as 5,30 levei o Enoir de volta para o berçário porque a Nair encontrava-se com o soro no braço, sendo retirado as $4 \mathrm{~h}$ do dia 12 , e o Enoir só as 8h que iniciou sua vivencia com a mamãe. Eu às 5,35 tomava o ônibus de volta para casa onde o Rudis e a Marica tinham arrumado os animais. (Aldo Schmidt, Diário n. 3, maio 1981)

O relato escrito nos mostra como o nascimento do filho aflorou em Aldo uma escrita carregada de sentimentos: o sentimento de ser pai e de tomar o "filhinho" nos braços, o primeiro banho, suas preocupações com a viagem de Nair até o hospital, a partilha da emoção do "primeiro herdeiro" com Nair... A escrita do dia 11 de maio de 1981 é rica em detalhes, contando em horas e minutos o sentimento de ser pai. Uma escrita que deixa transparecer o "coração" de Aldo, o sentimento e a emoção de ser pai.

Que tipo de homem, em uma sociedade patriarcal, se permite tal registro, carregado de emoção e felicidade? A resposta é: um homem como Aldo, agricultor, de pouca escolaridade, nascido e crescido na zona rural. Um homem sensível, emotivo e atento aos acontecimentos importantes da vida, como o nascimento dos filhos. Um homem que deixa registrado por escrito um dos acontecimentos mais intensos da vida e vivos da condição humana: o de ser pai.

No que diz respeito a registros sobre crianças, Foisil (1991, p. 351) apresenta como exemplo as escrituras privadas no final dos séculos XVII e durante 
o XVIII, nas quais são raros os relatos sobre crianças e, quando aparecem, são breves:

\begin{abstract}
As preocupações materiais com a criança nos primeiros anos de vida resumem-se essencialmente às despesas com nutriz, e, chegada a época da educação escolar, com coleio e pensão. Mas nada se diz sobre a graça ou a turbulência da criança, sobre seus progressos físicos, seus traços de caráter. Não há discurso afetivo.
\end{abstract}

Isso mostra que os registros de Aldo sobre os filhos aparecem de modo contrário ao que era comum nos séculos passados. A própria escrita de Aldo contradiz alguns estudos que indicam que as mulheres são as guardiãs da memória da vida privada (Perrot, 1989). Neste caso, essa memória familiar é “guardada” pelo homem, pelo pai.

Aldo é muito atento aos pormenores, tentando não deixar passar "em branco" momentos importantes da vida familiar. O que é, então, visto como uma "função" feminina é tomado, neste caso, pelas mãos masculinas. Poderia dizer que, segundo Perrot (1989, p. 15), isso é uma exceção, visto que:

Pela força das circunstâncias, pelo menos para as mulheres de antigamente, e pelo que resta de antigamente nas mulheres de hoje (o que não é pouco), é uma memória do privado, voltado para a família e o íntimo, aos quais elas foram delegadas por convenção e posição. Às mulheres cabe conservar os rastros das infâncias por elas governadas.

Os estudos de Perrot indicam que manter a memória da família, escrever o íntimo são práticas femininas, mas a prática de escrita aqui analisada contrapõe essa ideia. Aldo contraria essa regra feminina, na qual as mulheres é que cuidam dos arquivos familiares: "sobre a família e o cotidiano, que se pergunte às mulheres! Esse aspecto das coisas lhes cabe” (Perrot, 1989, p. 17). No caso de Aldo, é o oposto: o homem é que é o guardião das memórias e das histórias da família, revelando que não há regras, não há verdades, não há fórmulas de ser homem e de ser mulher, assim como não há, de um determinado ponto de vista, "escritas femininas e escritas masculinas”. É preciso considerar que a escrita, assim como a leitura, é uma prática complexa e diversa (Ribeiro, 2004). Revelar escritas como a de Aldo colabora na compreensão dessa complexidade e diversidade.

Nos diários de Aldo há um sentimento latente de afetividade e amor em relação aos filhos, principalmente no período da infância. Nos primeiros anos do filho mais velho, há registros sobre benzeduras, visitas dos familiares para conhecer o menino, batizado, primeiros passeios, entre outros, como no exemplo a seguir:

Dia 27 todo dia mudamos cebola no cerro, a Nair levou o Enoir, pela $1^{\text {a }}$ vez, para a lavoura, nos ajudaram o Nery, o Beto, a Vera, a Leia e a Maria Helena. (Aldo Schmidt, Diário n. 3, jul. 1981)

Passados dois meses de seu nascimento, Enoir vai à lavoura. Aldo registra esse fato em seu diário como um acontecimento de extrema importância: o herdeiro da prática da escrita é, também, o herdeiro do trabalho e do bem maior - a lavoura. Além disso, a primeira vez aparece novamente como o "rito que marca”, não só quando vai à lavoura, mas quando sai a passeio:

\footnotetext{
Dia 2 domingo de manhã dei umas volta para procurar uma vaca para comprar e na volta passei nos Pegoraros e olhei a pedra para o alicerce da casa, e de tarde fomos ao Culto na S. Paulo, sendo a $1^{\text {a }}$ vez que saímos com o Enoir a passeio. (Aldo Schmidt, Diário n. 2, ago. 1981)

Dia 28 (geadão) domingo de manhã eu biscatiei e levei as quitandas, a Nair fez limpesa em casa de tarde eu e o Enoir fizemos uma pandorga e levantamos ela ao vento e depois das $2 \mathrm{~h}$ fomos lá no Vô Schmidt. (Aldo Schmidt, Diário n. 5, ago. 1988)
}

De forma sensível, Aldo produz a escrita desses dias carregado de emoção. Isso fica evidente em especial no registro do primeiro passeio com o filho, da primeira vez que levam a criança na lavoura, da brincadeira de pandorga entre pai e filho, além de ou- 
tros relatos tomados pela sensibilidade. Como afirma Gomes (2004, p. 16), "é como se a escrita de si fosse um trabalho de ordenar, rearranjar e significar o trajeto de uma vida no suporte do texto, criando-se, através dele, um autor e uma narrativa”.

Da mesma forma que é descrito o nascimento do filho Enoir, também é o dia do nascimento do segundo filho, Mateus: o registro de nascimento no cartório, as visitas de parentes para conhecê-lo. Nas escritas de Aldo vão se alternando o trabalho na lavoura, o cotidiano com os filhos, os passeios, a saúde. Há dias em que o cuidado com a saúde, as doenças da infância mistura-se com o trabalho da lavoura, revelando a própria condição humana de ser e estar no mundo, da forma mais simples e mais complexa ao mesmo tempo, contraditoriamente, como é a própria vida. Em um dos registros encontra-se:

Dia 3 de manhã até as 9h eu lavrei a cabiceira da roça da divisa do Nilo e depois limpei o valo, a Nair ajeitou as coisas para nós ir a Pelotas de tarde, e depois do meio dia fomos a Pelotas consultar com o Mateus e o Enoir com a catapora. (Aldo Schmidt, Diário n. 5, jul. 1989)

Isso é próprio de alguém que registra a vida, pois a vida é feita de acontecimentos diversos, de experiências singulares. No caso de Aldo, roçar, capinar, limpar, consultar, passear, ou seja, viver. Registrar sua história, trazer o passado ao presente, dar vida às suas lembranças, deixar sua herança, ressignificar a sua vida, eis alguns dos sentidos da escrita diária para Aldo. Em uma analogia possível, pode-se dizer que escrever é como plantar e cuidar da lavoura: Aldo lançou uma semente, que cresceu e continua a se desenvolver. A semente passou a dar frutos entre os filhos, Enoir e Mateus, os filhos: também escrevem seus diários. É a vida que se reinventa na prática da escrita.

\section{Considerações finais}

Neste trabalho o objetivo principal foi analisar os sentidos da escrita de diários de um agricultor com pouca escolaridade, morador da zona rural.
Caracterizou-se por uma pesquisa no campo da cultura escrita e teve como foco principal os diários escritos por Aldo Schmidt.

Trabalhar com as escritas desse agricultor revela outros espaços e outras instâncias, desvelando alguns "mitos" da zona rural. Problematizar o tema da escrita numa perspectiva social e cultural não é tarefa fácil, pois envolve valores, crenças, sentimentos e usos dessa prática cultural. Nesta pesquisa, evidenciou-se que a escrita é tratada pelo agricultor como um bem simbólico, um valor, ou, como diz Lejeune (1997), uma forma de guardar as memórias de uma vida.

Por isso, o estudo procurou mostrar um caso singular: os sentidos da escrita não-escolar de um agricultor com baixa escolaridade. Nesse caso, podemos afirmar que, embora possua pouca escolaridade, ele apresenta alto grau de letramento, pois faz uso efetivo e cotidiano da leitura e da escrita. Nesse sentido, é interessante observar as escalas individuais na sociedade: quando falamos em história da cultura escrita, as fronteiras entre o popular e o erudito, alfabetizados e analfabetos, zona rural e zona urbana são aspectos que não estão tão distantes como parecem.

$\mathrm{O}$ que a escrita dos cadernos diários revela, quando se trata da história da cultura escrita? Poderíamos fazer uma analogia: os cadernos são a biblioteca e as escritas dessas pessoas, são os objetos que "guardam” a história. Muitas vezes, cometemos o erro de pensar que é só nas bibliotecas ou nos museus que estão os grandes patrimônios. Sem deixar de considerar a importância desses, referimo-nos aos diários encontrados na pesquisa como um grande patrimônio do escrito. Um patrimônio que será preservado e passado através das gerações para os filhos de Aldo, que atualmente também fazem seus registros diários. Um patrimônio do escrito deixado por um agricultor com pouca escolaridade mas que tem consciência de que pode "trazer o passado de volta ao presente” através de seus registros. Um patrimônio do escrito que nos dá nova significação para as práticas escolares de escrita: ela serve, além de tudo, para a vida! Arquivar sua história, reinventar-se, escrever para deixar os seus traços vividos e 
registrados, muito além do registro do trabalho na lavoura, eis as motivações de Aldo.

É importante dizer que este estudo também pretende ressignificar o contexto escolar e suas práticas de escrita. Conforme Vóvio (2005) e Souza (2006), “o que se quer é deixar de lado estereótipos sociais nos quais são enquadrados sujeitos e que, na maior parte das vezes, não permitem reconhecer ou identificar possibilidades individuais trilhadas em um campo social compartilhado" (p. 44-45). Por isso a prática de Aldo faz repensar o contexto da escola e as diversas funções da escrita em nossa sociedade: escrita enquanto estratégia de memória, como organização do pensamento, como correspondência, escrita da e na vida, registro do que se fez ou do que se fará no dia.

A escrita, no contexto escolar, deve ser também pensada na perspectiva social, e não apenas em uma perspectiva individual. Deve levar em conta os usos e as práticas que os indivíduos utilizam cotidianamente.

Finalizando, ressaltamos a importância da pesquisa que procura trazer contribuições à escrita como uma prática cultural. Através dessa prática, Aldo constrói uma identidade para si, através da escrita masculina, em um contexto singular: a zona rural. Para Gomes (2004, p. 11), “o ponto central a ser retido é que, através desses tipos de práticas culturais, o indivíduo moderno está constituindo uma identidade para si através dos seus documentos, cujo sentido passa a ser alargado”; e isso, para Aldo, é a certeza de existir através das palavras, contando à noite o que foi feito durante o dia, deixando um verdadeiro patrimônio do escrito.

\section{Referências bibliográficas}

ALBERT, Jean Pierre. La maison des écritures. In: FABRE, Daniel (Org.). Écritures ordinaires. Paris: Centre Georges Pompidou, Bibliothéque Publique d'Information, 1993. p. 33-94.

ARTIÈRES, Philippe. Arquivar a própria vida. Revista de Estudos Históricos, v. 11, n. 21, p. 9-34, 1998.

BAHIA, Joana D'Arc do Valle. O “tiro da bruxa”: identidade, magia e religião entre os camponeses pomeranos no Estado do Espírito Santo. Tese (Doutorado em Antropologia Social) - Museu
Nacional, Programa de Pós-Graduação em Antropologia Social, Universidade Federal do Rio de Janeiro, Rio de Janeiro, 2000. BRITTO, Luiz Percival Leme. Sociedade de cultura escrita, alfabetismo e participação. In: RIBEIRO, Vera Masagão (Org.). Letramento no Brasil. São Paulo: Global, 2004. p. 47- 63.

Letramento e alfabetização: implicações para a educação infantil. In: FARIA, Ana Lúcia Goulart de; MELLO, Suely Amaral (Orgs.). O mundo da escrita no universo da pequena infância. Campinas: Autores Associados, 2005. p. 5-21.

CHARTIER, Roger. A aventura do livro do leitor ao navegador. São Paulo: UNESP, 1999.

Cultura escrita, literatura e história. Porto Alegre:

Artmed, 2001.

Inscrever e apagar. Cultura escrita e literatura. São Paulo: UNESP, 2007.

DIAS, Helena Caminhas. Agricultores e literacia: relação com a informação institucional e vida quotidiana no centro litoral. In: BENAVENTE, Ana (Coord.). A literacia em Portugal: resultados de uma pesquisa extensiva e monográfica. Portugal: Fundação Calouste Gulbenkian, Serviço de Educação, Conselho Nacional de Educação, 1996. p. 239-265.

FABRE, Daniel (Org.). Écritures ordinaires. Paris: Centre Georges Pompidou, Bibliothéque Publique d' Information, 1993. p. 11-94. FOISIL, Madeleine. A escritura do foro privado. In: CHARTIER, Roger. História da vida privada 3: da Renascença ao Século das Luzes. São Paulo: Companhia das Letras, 1991. p. 331-369.

GOMES, Angela de Castro. Escrita de si, escrita da história: a título de prólogo. Rio de Janeiro: Editora FGV, 2004.

GÓMEZ, Antonio Castillo. Historia de la cultura escrita. Del próximo Oriente Antiguo a la sociedad informatizada. Gijón: Trea, 2001. Historia de la cultura escrita: ideas para el debate. Revista Brasileira de História da Educação, Campinas: SBHE/ Autores Associados, n. 5, p. 93-124, jan./jul. 2003.

Leer y escribir en la era de Internet: problemas e desafíos de la cultura escrita. Educação e Realidade, v. 29, n. 2, p. 41-54, jul./dez. 2004.

KLEIMAN, Ângela. Introdução: o que é letramento? Modelos de letramento e as práticas de alfabetização na escola. In: (Org.). Os significados do letramento. Campinas: Mercado de Letras, 2001. p. 15-61.

.; MATENCIO, Maria de Lourdes M. Apresentação. In: Letramento e formação do professor. Campinas:

Mercado de Letras, 2005. p. 7-16. 
LAHIRE, Bernard. Homem plural. Os determinantes da ação. Petrópolis: Vozes, 2002.

. Retratos sociológicos. Disposições e variações individuais. Porto Alegre: Artmed, 2004.

. A cultura dos indivíduos. Porto Alegre: Artmed, 2006.

LEJEUNE, Philippe. O guarda-memória. Revista de Estudos Históricos, Rio de Janeiro, n. 19, p. 1-8, 1997. Disponível em: $<$ http://cpdoc.fgv.br/revista/arq/213.pdf > . Acesso em: 22 jun. 2007. MIGNOT, Ana Chrystina Venâncio; BASTOS, Maria Helena Câmara; CUNHA, Maria Teresa Santos (Orgs.). Refúgios do $E u$ : educação, história, escritura autobiográfica. Florianópolis: Mulheres, 2000.

PERROT, Michelle. Práticas da memória feminina. Revista Brasileira de História, São Paulo, v. 9, n. 18, p. 9-18, ago./set. 1989. Caroline, uma jovem do Faubourg Saint-Germain durante o Segundo Império. In: As mulheres ou os silêncios da história. São Paulo: EDUSC, 2005. p. 89-146.

PETRUCCI, Armando. Alfabetismo, escritura, sociedad. Barcelona: Gedisa, 1999.

RIBEIRO, Vera Masagão. Alfabetismo e atitudes. Pesquisa junto a jovens e adultos paulistas. Revista Brasileira de Educação, v. 9, n. 9, p. 5-15, set./dez. 1998.

Por mais e melhores leitores: uma introdução. In: (Org.). Letramento no Brasil. São Paulo: Global, 2004. p. 9-29.

. Uma perspectiva para o estudo do letramento: lições de um projeto em curso. In: KLEIMAN, Ângela; MATENCIO, Maria de Lourdes M. Letramento e formação do professor. Campinas: Mercado de Letras, 2005. p. 17-39.

SILVA, Maria Emília Lins; BATISTA, Antônio Augusto Gomes. Escritas para si, escritas para o outro nas memórias de um grupo de docentes. In: REUNIÃO ANUAL DA ANPED, 28., Caxambu, 2005. Anais... Caxambu: ANPEd, 2005. 1 CD-ROM.

SOARES, Magda. Língua escrita, sociedade e cultura. Revista Brasileira de Educação, n. 0, p. 5-16, set./dez. 1995.

Letramento. Um tema em três gêneros. Belo Horizonte: Autêntica, 1998.

Letramento e escolarização. In: RIBEIRO, Vera

Masagão (Org.). Letramento no Brasil: reflexões a partir do INAF 2001. São Paulo: Global, 2004. p. 89-113.

SOUZA, Elizeu Clementino de. O conhecimento de si: estágio e narrativas de formação de professores. Rio de Janeiro: DP\&A; Salvador: UNEB, 2006.
THIES, Vania Grim. Arando a terra, registrando a vida: os sentidos da escrita de diários na vida de dois agricultores. Dissertação (Mestrado em Educação) - Programa de Pós-Graduação em Educação, Faculdade de Educação, Universidade Federal de Pelotas, Pelotas, 2008.

VIÑAO FRAGO, António. Alfabetização na sociedade e na história. Porto Alegre: Artes Médicas, 1993.

Leer y escribir. Historia de las prácticas culturales. México: Fundación Educación Voces e Vuelos, 1999.

. Bibliotecas, “culturas escolares” y formación de professores. Educação e Realidade, v. 29, n. 2, p. 65-88, jul./dez. 2004. VÓVIO, Cláudia Lemos; SOUZA, Ana Lúcia Silva. Desafios metodológicos em pesquisas sobre letramento. In: KLEIMAN, Ângela; MATENCIO, Maria de Lourdes M. Letramento e formação do professor. Campinas: Mercado de Letras, 2005. p. 41-64.

VA NIA GRIM THIES, mestre em educação pelo Programa de Pós-Graduação em Educação da Faculdade de Educação da Universidade Federal de Pelotas (UFPel) e doutoranda no mesmo programa, é pesquisadora do grupo História da Alfabetização, Leitura, Escrita e dos Livros Escolares (HISALES). Publicações recentes: A escrita no cotidiano da zona rural: os diários de dois agricultores (Roteiro, Joaçaba, v. 33, p. 101-125, 2008); Práticas de leitura de uma família de agricultores em Pelotas (Alfabetização e Letramento, Pelotas, v. 1, p. 167-186, 2008); A pesquisa com diários de agricultores (1972-2004): refletindo sobre uma metodologia de investigação no campo da cultura escrita (In: CONGRESSO BRASILEIRO DE HISTÓRIA DA EDUCAÇÃO, 5., Aracaju, 2008. Anais... Aracaju: s.ed., 2008. v. 1. p. 1-14). Pesquisa em andamento: "Práticas de letramento não-escolar no contexto da zona rural: as escritas dos irmãos Schmidt”. E-mail: vaniagrim@yahoo.com.br

ELIANE PERES, doutora em educação pela Universidade Federal de Minas Gerais (UFMG), com estágio de pesquisa na Universidade de Lisboa (Portugal, 1999), é professora do Departamento de Ensino da Faculdade de Educação da Universidade Federal de Pelotas (UFPel); desde 2001 atua no Programa de Pós-Graduação em Educação, onde é líder do grupo de pesquisa História da Alfabetização, Leitura, Escrita e dos Livros Escolares (HISALES, Conselho Nacional de Desenvolvimento Científico e Tecnológico - CNPq). Publicações recentes: Autoras de obras didáticas e livros para o ensino da leitura produzidos no Rio Grande do Sul: contribuições à história da alfabetização, 1950-1970 (Edu- 
cação, UNISINOS, v. 12, p. 111-121, 2008); Marcas da infância em cadernos escolares de crianças em processo de alfabetização (In: MIGNOT, Ana Chrystina Venancio (Org.). Não me esqueça num canto qualquer. Rio de Janeiro: Laboratório Educação e Imagem, 2008. v. 1. p. 1-12); em coautoria com FACIN, Helenara: Nelly Cunha: sua vida foi escrever e ensinar, seu legado são seus livros didáticos (In: ABRAHÃO, Maria Helena Menna Barreto (Org.). Educadores sul-rio-grandenses: muita vida nas histórias de vida. Porto Alegre: EDIPUCRS, 2008. v. 1. p. 225-240); A trajetória de uma investigação sobre memórias de alfabetização: a experiência do grupo de pesquisa HISALES da FaE/UFPel (In: SOUZA, Elizeu Clementino de; PASSEGGI, Maria da Conceição; ABRAHÃO, Maria Helena Menna Barreto (Orgs.). Pesquisa (auto)biográfica e práticas de formação. São Paulo: Paulus; Natal: Editora da UFRN,
2008. v. 4. p. 193-208). Pesquisa em andamento, financiada pelo CNPq: "Implantação do ensino fundamental de nove anos em municípios da Região Sul do Rio Grande do Sul”. Participa de outras duas pesquisas interinstitucionais: "Por uma teoria e uma história da escola primária no Brasil: investigações comparadas sobre a escola graduada (1870-1950)”, coordenada pela professora Rosa Fátima de Souza, e "Cartilhas escolares: ideários, práticas pedagógicas e editoriais; a história da alfabetização e das cartilhas (Minas Gerais, Rio Grande do Sul e Mato Grosso, 1870-1980)”, um projeto interinstitucional UFPel, UFMG e Universidade Federal de Mato Grosso (UFMT).E-mail: etperes@terra.com.br

Recebido em outubro de 2008 Aprovado em março de 2009 


\section{Resumos/Abstracts/Resumens}

Vania Grim Thies e Eliane Peres

Quando a escrita ressignifica a vida: diários de um agricultor - uma prática de escrita "masculina"

Este trabalho analisa diários escritos por um agricultor gaúcho, 61 anos, com escolarização primária, que há 36 anos (1972-2008) "registra sua vida por escrito”, escrevendo rigorosamente todos os dias e deixando marcas de sua própria história através da escrita. A metodologia utilizada é a análise de dez diários juntamente com entrevistas semiestruturadas. O referencial teórico está apoiado em autores ligados à história da cultura escrita e ao campo das práticas de letramento. Algumas das conclusões desse trabalho indicam que a escrita dos diários é, para o agricultor, "uma forma de existir no cotidiano”, de registrar a sua história e a da sua família, de deixar marcas do passado como uma "herança" às novas gerações. Entendemos que este estudo traz contribuições ao campo da cultura escrita na medida em que apresenta a escrita como uma prática social e cultural complexa e significativa. Nesse sentido, tratamos os diários como um patrimônio do escrito.

Palavras-chave: cultura escrita; letramento; agricultor; diários.

\section{When writing gives a new meaning} to life: diaries of a farmer - a "male" writing practice

This work analyzes diaries written by a farmer from Rio Grande do Sul, 61 years old, with primary schooling, that has been for 36 years (19722008) "recording his life through writing”, writing rigorously every day and leaving marks from his own history through the writing. The methodology used is the analysis of ten diaries along with semi-structuralized interviews. The theoretical reference is based on authors linked to the history of the written culture and to the field of the literacy practices. Some of the conclusions reached by this work indicate that the writing of the diaries is, for the farmer, " $a$ way of being in the everyday life", of recording his history and the history of his family, a way of leaving marks from the past as an "inheritance" to new generations. We understand that this study contributes to the field of written culture as it presents writing as complex and meaningful social and cultural practice. Therefore, we deal with the diaries as a heritage of the written.

Key words: written culture; literacy; farmer; diaries.

\section{Cuando la escrita resignifica la}

vida: diarios de un agricultor - una práctica de escrita "masculina” Este trabajo analiza diarios escritos por un agricultor gaucho, 61 años con escolaridad primaria y que hace 36 años (1972-2008) "registraba su vida por escrito" escribiendo, rigurosamente, todos los días y dejando huellas de su propia historia a través de la escrita. La metodología utilizada es el análisis de diez diarios junto con entrevistas 
semiestructuradas. El referencial teórico está apoyado en autores vinculados a la historia de la cultura escrita y al campo de las prácticas de letrar. Algunas de las conclusiones de ese trabajo indican que la escrita de los diarios es, para el agricultor, "una forma de existir en el cotidiano”, de registrar su historia y la de su familia, de dejar huellas del pasado como una "herencia" a las nuevas generaciones. Entendemos que ese estudio trae contribuciones al campo de la cultura escrita en la medida que presenta la escrita como una compleja y significativa práctica social y cultural. En ese sentido, tratamos a los diarios como un patrimonio de lo escrito.

Palabras claves: cultura escrita; letrar; agricultor; diários.

Roberta Araújo Teixeira

\section{Espaços, recursos escolares e} habilidades de leitura de estudantes da rede pública municipal do Rio de Janeiro: estudo exploratório O artigo traz os resultados de um estudo exploratório realizado no ano de 2007 em três escolas municipais do Rio de Janeiro participantes do Projeto GERES (Estudo da Geração Escolar 2005). Considerando que os espaços escolares possuem importante dimensão educativa e que a materialidade da escola é fator relevante na constituição de práticas escolares capazes de constranger ou de estimular conhecimentos e competências, buscou-se compreender, no interior das escolas investigadas, o conjunto de fazeres pedagógicos ativados que guardam relação mais direta com o desenvolvimento de habilidades básicas de leitura e escrita. Foram utilizados registros fotográficos de salas de aula, cantinhos de leitura, murais e salas de leitura como fonte de dados. Identificaram-se aspectos relevantes das instituições pesquisadas pautados na natureza, disposição, usos e funções de espaços e objetos relacionados à promoção da leitura, contribuindo para o entendimento da eficácia escolar do ponto de vista dos discursos visuais da escola como fatores promotores de aprendizagem.

Palavras-chave: espaços escolares; eficácia escolar; habilidades de leitura.

Spaces, school resources and reading skills of students from the Rio de Janeiro municipal school system: an exploratory study

This paper presents the findings of an exploratory study conducted in 2007 in three municipal schools in Rio de Janeiro, Brazil, all participants in the 2005 School Generation Study (GERES) Project. As school spaces possess an important educational dimension and material aspects of school play a leading role in establishing educational practices that can curb or spur the dissemination of knowledge and skills, the set of teaching tasks examined in these schools focused mainly on the development of basic reading and writing skills. Data sources included photographs of classrooms, book nooks, bulletin boards and reading rooms, with significant aspects of these institutions identified by the types, layouts, uses and functions of spaces and objects designed to encourage reading. This analysis helps build up a better understanding of school effectiveness from the standpoint of the visual discourses presented by schools as factors underpinning the learning process.

Key words: school spaces; school effectiveness; reading skills.

Espacios, recursos escolares y habilidades de lectura de estudiantes de la red pública municipal de Rio de Janeiro: estudio exploratorio El artículo trae los resultados de un estudio exploratorio realizado en el año de 2007 en tres escuelas municipales de Rio de Janeiro participando del Proyecto GERES (Estudio de la Generación Escolar 2005). Considerando que los espacios escolares poseen importante dimensión en la educación y que la materialidad de la escuela es factor relevante en la constitución de prácticas escolares capaces de constreñir o de estimular conocimientos y competencias, se buscó comprender, en el interior de las escuelas investigadas, el conjunto de trabajos pedagógicos activados que guardan relación más directa con el desarrollo de habilidades básicas de lectura y escrita. Fueron utilizados registros fotográficos de salas de clase, rincones de lectura, murales y salas de lectura como fuente de datos. Se identificaron aspectos relevantes de las instituciones pesquisadas pautados en la naturaleza, disposición, usos $y$ funciones de espacios e objetos relacionados a la promoción de la lectura, contribuyendo para el entendimiento de la eficacia escolar bajo el punto de vista de los discursos visuales de la escuela como factores promotores de aprendizaje.

Palabras claves: espacios escolares; eficacia escolar; habilidades de lectura.

Maria Clara Di Pierro e

Marcia Regina Andrade

Escolarização em assentamentos no estado de São Paulo: uma análise da Pesquisa Nacional de Educação na

\section{Reforma Agrária 2004}

O estudo sobre a escolarização nos assentamentos rurais do estado de São Paulo, com base nos dados da Pesquisa Nacional de Educação na Reforma Agrária 2004, constatou que o direito à educação só estava assegurado às crianças que frequentavam as séries iniciais do ensino fundamental; nos demais níveis e modalidades, inclusive a educação de jovens e adultos, a oferta 